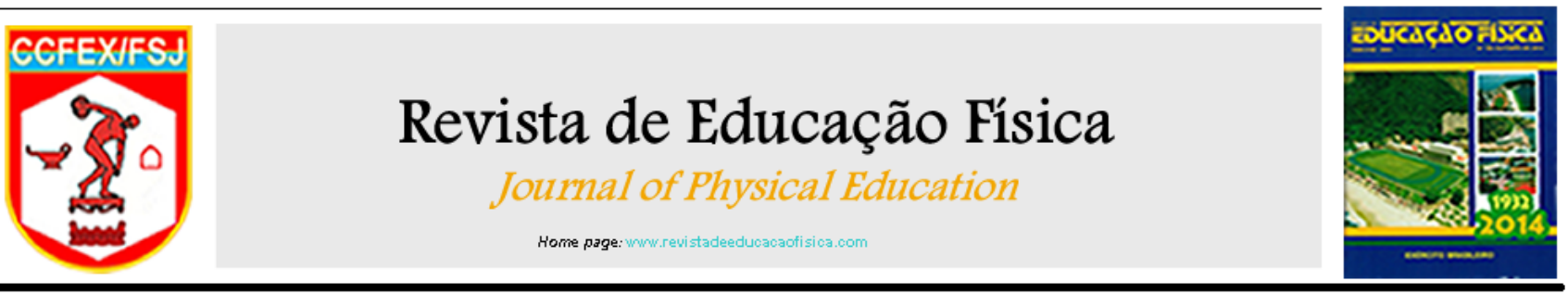

Resumo

\title{
Efeitos do treinamento de agachamento na redução de assimetrias e distribuição do peso corporal
}

Gabriel Ferreira Mattos Bsci, Rodrigo Rico Bini PhD

Introdução: A literatura carece quando relacionado aos efeitos sobre o peso corporal e sua diferença de distribuição entre os membros inferiores.

Objetivo: A redução de assimetrias bilaterais de membros inferiores em relação às forças de reação no solo durante o exercício de agachamento livre e a melhora na distribuição do peso corporal através de um treinamento de agachamento bilateral livre são os objetivos deste estudo.

Métodos: Participaram do estudo oito indivíduos do sexo masculino $[25,9 \pm 2$ anos, $81,6 \pm 10,8 \mathrm{~kg}, 176,3 \pm 7,2 \mathrm{~cm}$ ) que foram selecionados por apresentarem diferença na distribuição de peso corporal e/ou diferença na resultante das forças de reação do solo entre os membros inferiores maior ou igual a $10 \%$. Foram submetidos a um treinamento de agachamento de três semanas, três dias em cada uma. 0 agachamento foi realizado de forma livre, no qual levantaram uma carga total de aproximadamente $120 \%$ de seu peso corporal, ou seja, $20 \%$ de carga adicional. 0 teste avaliou o número de repetições realizadas em três séries de repetições máximas com intervalo de 5 minutos entre elas. Ao final da intervenção, comparou-se a distribuição do peso corporal entre os membros inferiores pré e pós-treinamento (estático) e a força vertical de reação do solo na primeira, quinta e nona sessões (dinâmico). Os efeitos do treinamento sobre a distribuição do peso corporal foi avaliado por meio de um teste U de MannWhitney, enquanto ANOVA foi aplicada para a comparação das assimetrias entre as sessões de treinamento ( $1^{\underline{a}}$ vs. $5^{\underline{a}}$ vs. $9^{a}$ seção) com nível de significância de $5 \%$.

Resultados: Tanto na análise da assimetria estática quanto para as assimetrias dinâmicas, não houve efeito significativo do treinamento sobre estas medidas ( $p$ $=0,14$ e $\mathrm{p}=0,91$, respectivamente).

Conclusão: 0 treinamento de agachamento proposto não apresentou melhora na redução de assimetria bilateral para membros inferiores quando analisado comparativamente. 